\title{
Parasitic Strip Loaded Dual Band Notch Circular Monopole Antenna with Defected Ground Structure
}

\author{
P Syam Sundar, Sarat K Kotamraju, B T P Madhav, M Sreehari, K Raghavendra Rao, \\ L Prathyusha, Y Pravallika \\ Department of ECE, K L University, AP, India
}

\begin{tabular}{l}
\hline \hline Article Info \\
\hline Article history: \\
Received Mar 18, 2016 \\
Revised Jun 29, 2016 \\
Accepted Jul 13, 2016
\end{tabular}

Keyword:

Defected ground structure

Dual notch band

Parasitic slits

Parasitic strip

Tuning stub

\begin{abstract}
In this article a parasitic strip loaded monopole antennas are designed to notch dual and triple bands. The designed models are constructed on one side of the substrate material and on the other end defected ground structures are implemented. The basic antenna comprises a tuning stub and a ground plane with tapered shape slot as DGS. Another model is constructed with circular monopole radiating element on front side and similar kind of ground structure used in the basic rectangular tuning stub antenna. To create notched bands with tuning stubs, two symmetrical parasitic slits are placed inside the slot of the ground plane. The basic model is of the rectangular stub notching triple band and the circular tuning stub antenna notching dual band. Dual band notched circular tuning stub antenna is prototyped on FR4 substrate and measured results from vector network analyzer are compared with simulation results of HFSS for validation.
\end{abstract}

Copyright $@ 2016$ Institute of Advanced Engineering and Science. All rights reserved.

\section{Corresponding Author:}

B T P Madhav, Professor, Department of ECE, K L University, AP, India.

Email: btpmadhav@kluniversity.in

\section{INTRODUCTION}

Microstrip Antennas are used in an extensive manner in current communication system because of advantages such as low profile and can be used in multi-band and wide-band applications [1]-[4]. Its applications are mainly used by the antenna engineers in every part of the world. In the entire wideband some bands are rejected using notched antennas. Many techniques are available in literature to notch certain frequency bands [5]-[9]. The prevailing methods including cutting a slot on the patch, inserting a slit on the patch, using conductor backed plane, and embedding a tuning stub within a slot on the patch are used by the researchers in so many cases. Moreover, band rejection characteristics are generated by using a resonator at the center of antenna and with a pair of inverted $\mathrm{L}$ shaped slots on the ground plane. Defected ground structures will provide additional resonant bands when combined with the antenna models [10]. Detected Ground Structures (DGS) as the name implies to some compact geometries, commonly known as "unit cell" etched out as a single defect or in periodic configuration with small period number on the ground plane of a microwave printed circuit board (M-PCB) to attribute a feature of stopping wave propagation through the substrate over a frequency range. Thus a DGS can be described as a unit cell EBG or an EBG with limited shapes and sizes with different frequency responses and equivalent circuit parameters. The presence of DGS under a printed transmission line actually perturbs the current distribution in the ground plane and thus modifies the equivalent line parameters over the defected region [11].

Many multiple (dual, triple, quadruple) band-notched UWB antenna topologies have also been given in recent literature. Many UWB applications require more than one notch band so that non interfering frequencies applications can be obtained [12]-[13]. The usage of split-ring resonators (SRRs) and 
complementary split-ring resonators (CSRRs) in order to design reconfigurable multiple band-notched UWB antennas have also been reported in [14]-[15].

In this paper a compact tuning stub and parasitic strips loaded notch band antennas are designed to notch multiple bands. To notch particular bands, an angle shaped parasitic slit is asymmetrically etched out along with the tuning stub. Two symmetrical parasitic slits are placed inside the slot to create additional notch band. The detailed geometrical construction of the antenna models is presented in the subsequent section.

\section{MATERIALS AND METHOD}

Figure 1 and 2 shows the designed notch band antennas with rectangular and circular tuning stubs. Both these models are having one angle shaped parasitic slit etched out along with the tuning stub and two symmetrical parasitic slits inside the slot of ground plane. The proposed models are compact in size and use a simple filter type structures to create notch bands. The designed models dimensional characteristics with respect to parameters are presented in table1. To achieve 50 ohms characteristic impedance, the width and length of the feed line are chosen as $3 \mathrm{~mm}$ and $6 \mathrm{~mm}$ respectively. To achieve good impedance matching a tapered shape slot in the ground plane is coupled to tuning stub. Dual band notched antenna is prototyped on FR4 substrate with dielectric constant 4.4 and occupies the total dimension of $22 \times 24 \times 1.6 \mathrm{~mm}$.
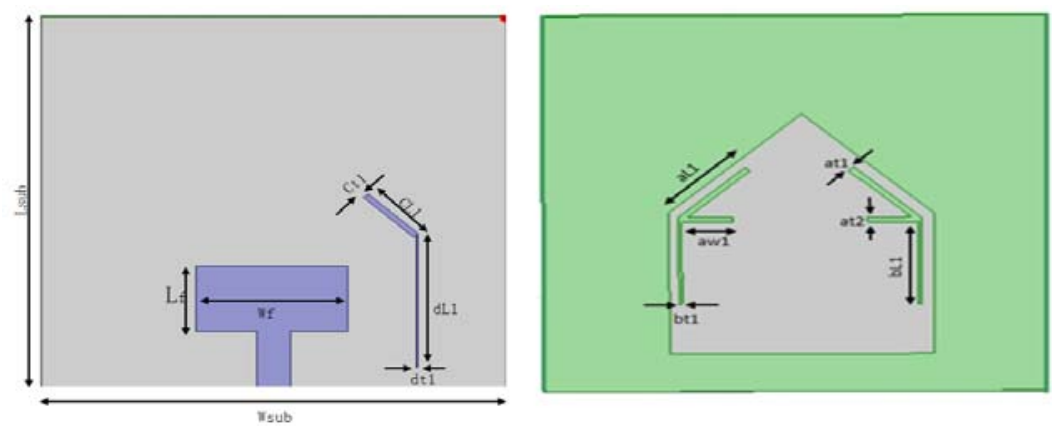

Figure 1. Rectangular Tuning Stub Notch Antenna

The angle shaped slit on the front side of the antenna has two portions. One curved arm and one vertical arm placed asymmetrically to get notch band characteristics. Each of the symmetrical parasitic slits consists of a half triangle portion and a vertical portion. Despite insertion of parasitic slits, the overall antenna dimension remains the same and no extra space is required for the filter structure.

Table 1. Designed Antennas Dimensions

\begin{tabular}{ccccccccccccccccc}
\hline Lsub & Wsub & Lf & Wf & Rp & CL1 & CT1 & dL1 & dt1 & aL1 & aw1 & at1 & at2 & bL1 & bt1 \\
\hline 40 & 40 & 6 & 3 & 6 & 6.05 & 0.55 & 14.5 & 0.1 & 7.45 & 4 & 0.5 & 0.5 & 8.7 & 0.2 \\
\hline
\end{tabular}
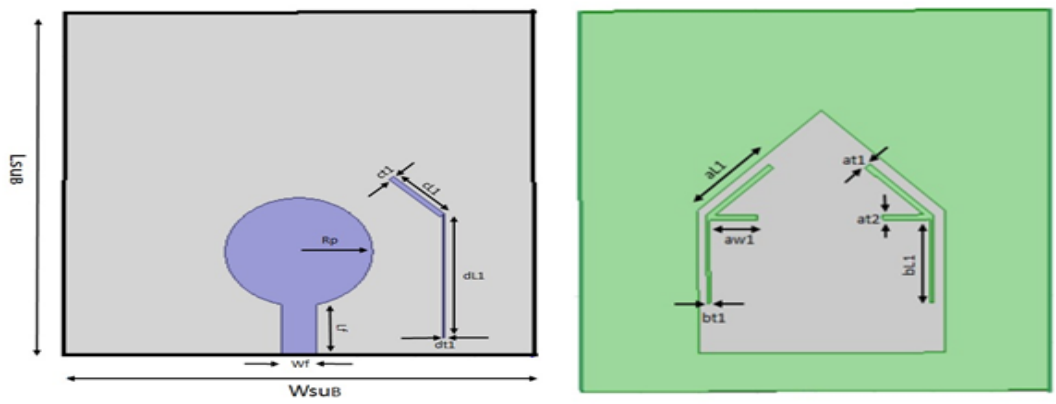

Figure 2. Circular Tuning Stub Notch Antenna 


\section{RESULTS AND DISCUSSION}

The designed models on FR4 substrate are simulated using finite element method based electromagnetic tool HFSS. Initially to find out the pass bands and notch bands the reflection coefficient curve is constructed and presented in Figure 3. The $S_{11}$ curve shown in figure3 gives the clear picture regarding operating bands and the corresponding designed notch bands. Antenna model1 is resonating at triple band and notching the frequencies from 3.6 to $4.6 \mathrm{GHz}, 5$ to $6.8 \mathrm{GHz}$ and 9.5 to $10.5 \mathrm{GHz}$. At second resonant frequency antenna model 1 is showing large bandwidth of $3 \mathrm{GHz}$ and an impedance bandwidth of $35.2 \%$. Antenna model 2 is notching the higher frequency band from 10.2 to $10.8 \mathrm{GHz}$ and 12 to $15 \mathrm{GHz}$. The second model is showing an impedance bandwidth of $36.8 \%$ at fundamental resonant frequency and $13 \%$ at second resonant frequency. Figure 4 shows the VSWR characteristics of the designed antenna models with respect to operation band of frequencies. At pass band both the antennas are showing 2:1 ratio of VSWR and at notch bands the rejection ratio is very high. Figure 5 shows the impedance characteristics of designed models with change in frequency. At pass bands antennas are showing average impedance of 35 ohms and at notch bands an average impedance of 20 ohms.

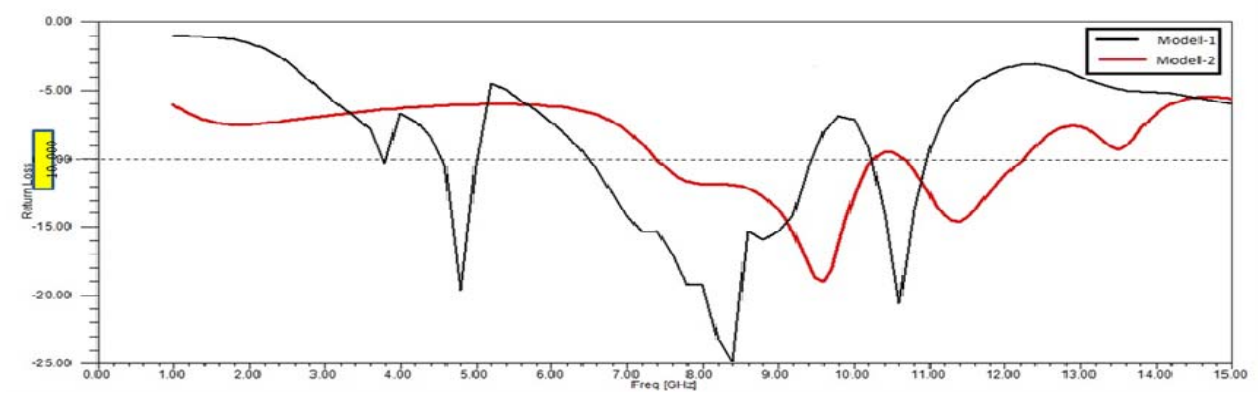

Figure 3. Reflection Coefficient of designed antenna models

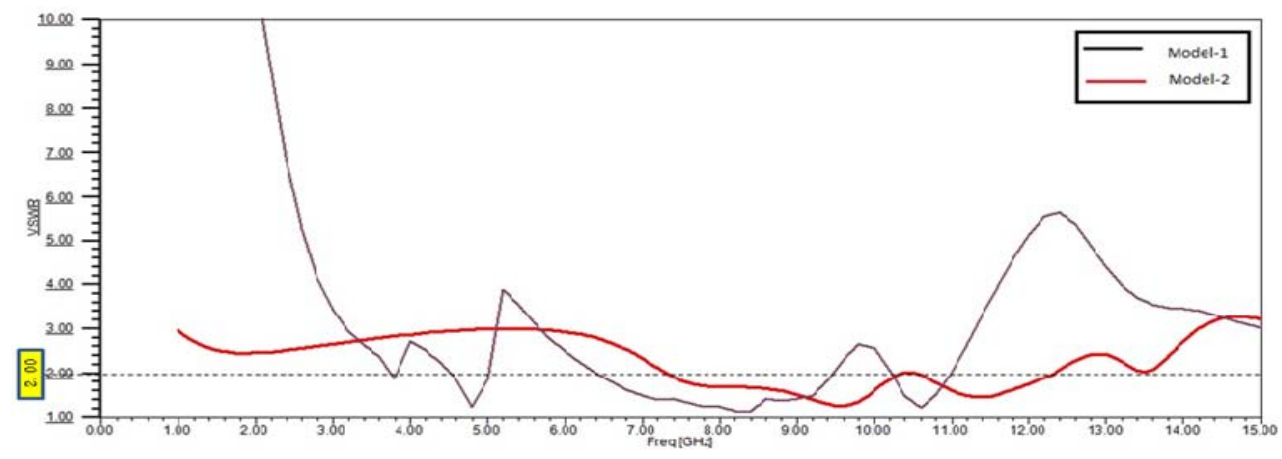

Figure 4. VSWR Vs Frequency

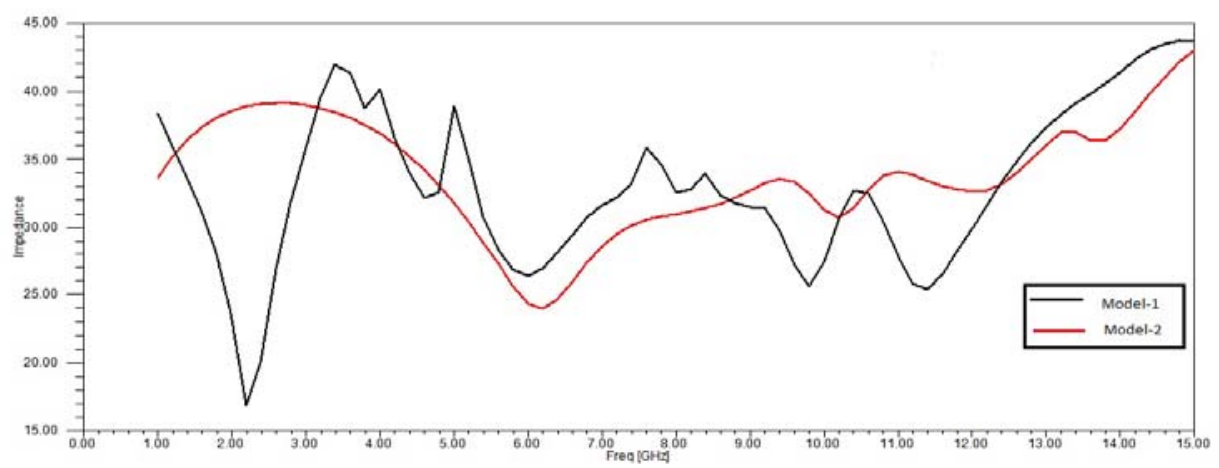

Figure 5. Impedance Vs Frequency 
The radiation characteristics of any antenna can be described completely with their radiation pattern curves in E plane and $\mathrm{H}$ plane. Figure 6 shows the radiation pattern of the rectangular stub antenna in $\mathrm{E}$ plane and $\mathrm{H}$ plane at $4.8 \mathrm{GHz}$. Figure 7 shows the radiation characteristics of antenna model 1 at $8.5 \mathrm{GHz}$. It is being observed that at higher frequency of operation a quasi-omnidirectional radiation pattern is observed in $\mathrm{H}$ plane, whereas at lower operating band the radiation pattern is directive in nature. Figure 8 and 9 shows the radiation characteristics of antenna model 2 at $9.6 \mathrm{GHz}$ and $11.4 \mathrm{GHz}$. At lower operating band antenna is showing quasi omnidirectional radiation whereas at higher operating band in the $\mathrm{H}$ plane the pattern is omnidirectional. The E plane pattern at lower operating band is somehow disturbed and not giving a complete directive radiation pattern.
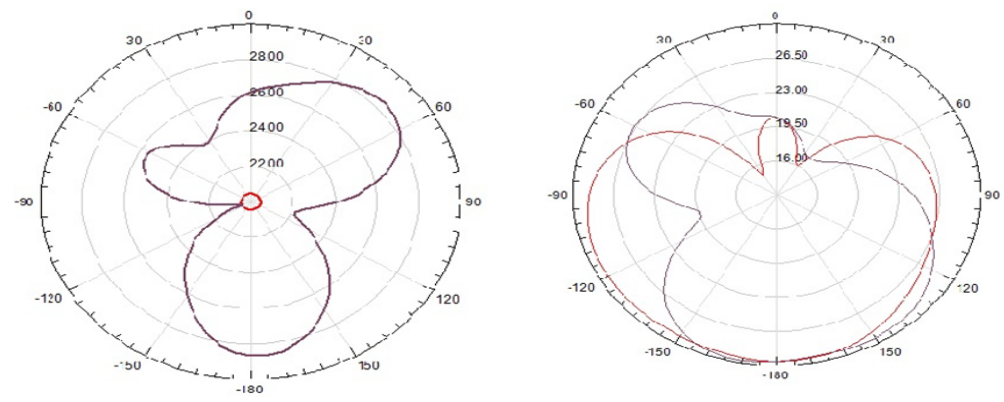

Figure 6. Radiation Pattern of model 1 at $4.8 \mathrm{GHz}$
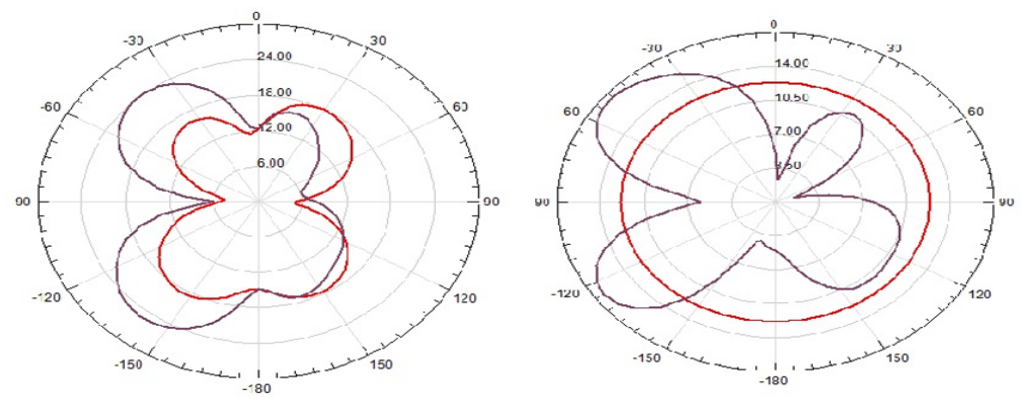

Figure 7. Radiation Pattern of Model 1 at $8.5 \mathrm{GHz}$
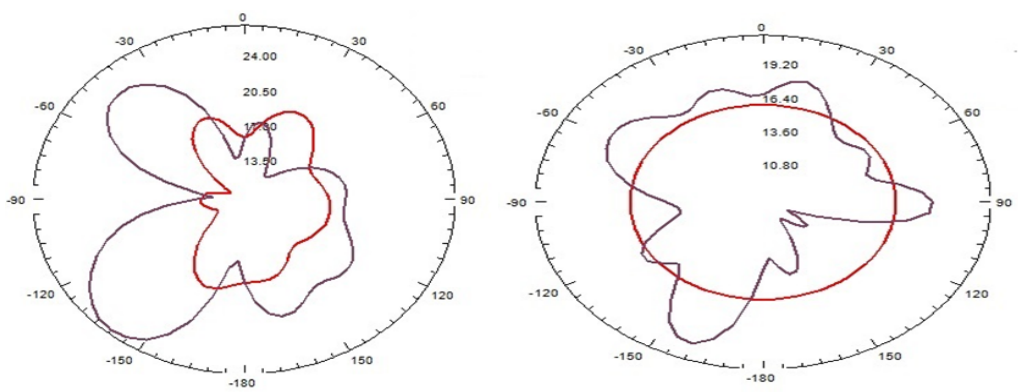

Figure 8. Radiation Pattern of Model 2 at $9.6 \mathrm{GHz}$ 


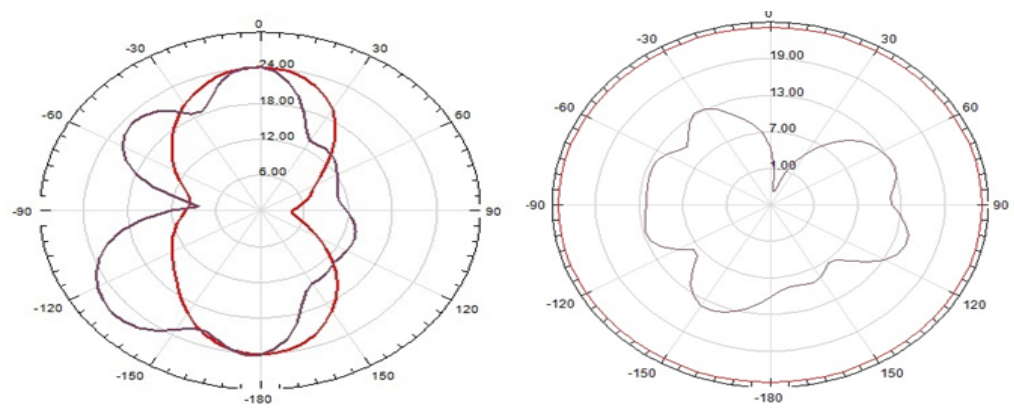

Figure 9. Radiation Pattern of Model 2 at $11.4 \mathrm{GHz}$

Figure 10 shows the surface current distribution of the antenna model at $4.8 \mathrm{GHz}$ and $8.5 \mathrm{GHz}$ respectively. At higher band the radiating patch is giving more intensity with directive radiation whereas at lower band most of the current distribution is because of feedline and the surrounded tapered ground plane nearer to the patch. Figure11 shows the surface current distribution of antenna model 2. It is clear from these figures that the currents are strongly concentrated around the angle shaped parasitic slit and the flow of current on the slit are opposite when you compare the model2 at different frequencies. Therefore, the total effective radiation is very weak and thus a notched band is created at higher frequency band.
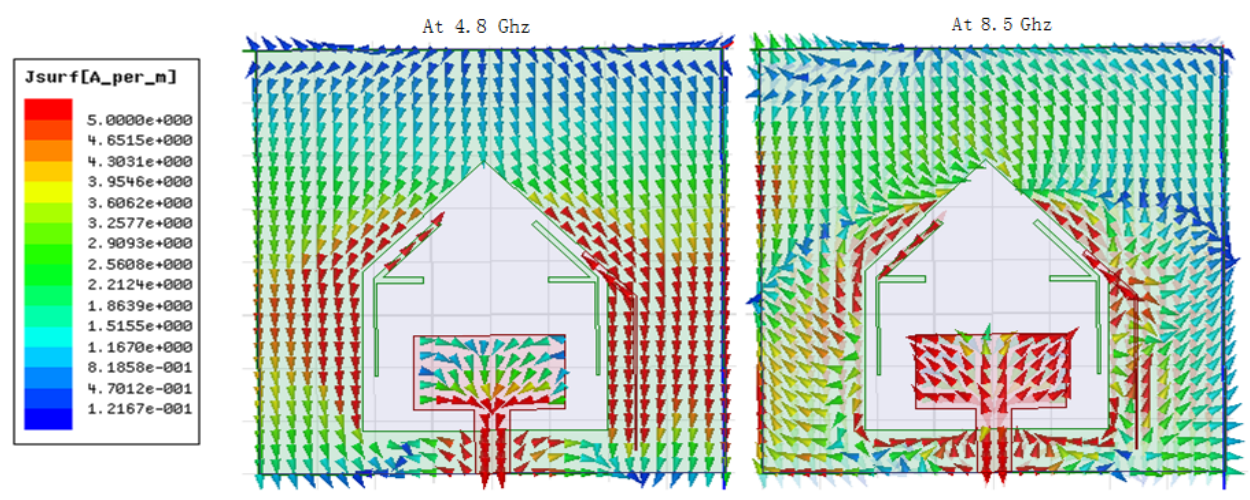

Figure 10. Surface current distribution of Antenna Model 1 at 4.8 and $8.5 \mathrm{GHz}$

At $9.6 \mathrm{Ghz}$
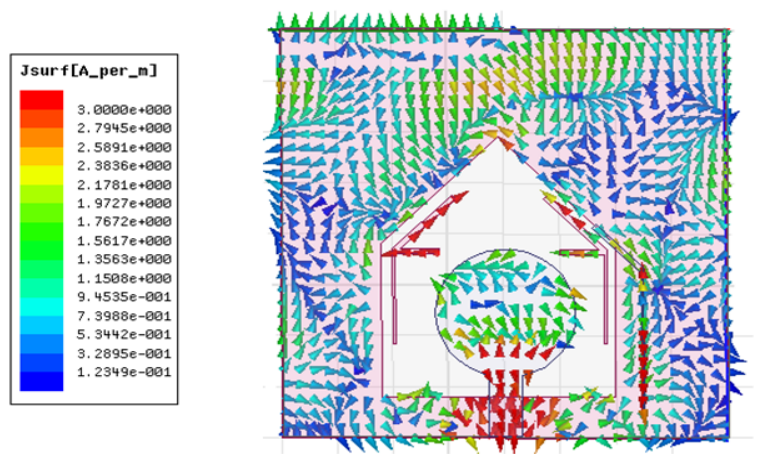

At $11.4 \mathrm{Ghz}$

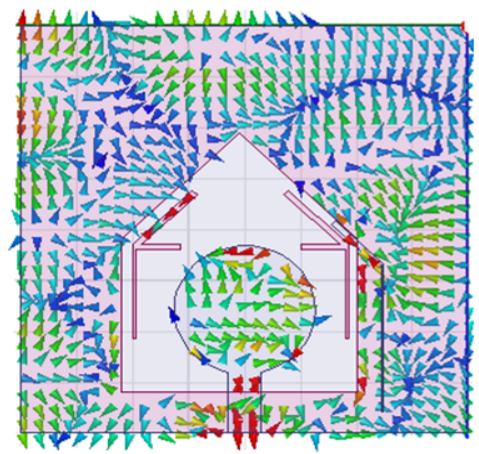

Figure 11. Surface current distribution of Antenna Model 2 at 9.6 and $11.4 \mathrm{GHz}$

Figure 12 shows the three dimensional radiation characteristics of the antenna models. It is being observed that rectangular stub antenna is giving a maximum gain of $3 \mathrm{~dB}$ in XY plane whereas antenna model 2 of circular stub is giving maximum gain of $1.3 \mathrm{~dB}$ in $\mathrm{XZ}$ plane. Figure 13 shows the frequency Vs Gain plot of the designed antennas at their corresponding operating bands. Antenna1 is showing more gain 
compared to Antenna model 2. But directivity of antenna model 2 is more when compared with antenna model1 from Figure 14.
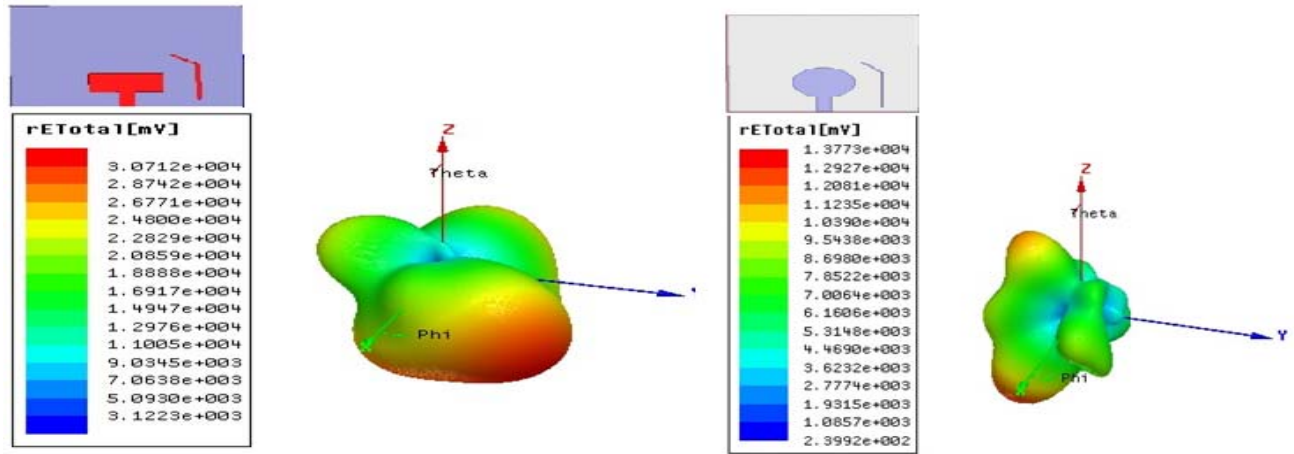

Figure 12. Three dimensional radiation pattern view of model 1 and 2

The parametric analysis of antenna model2 with respect to width of the feedline is presented in Figure 15 by keeping length of the feed line is constant. For the optimized dimension of width $2 \mathrm{~mm}$ antenna is showing excellent reflection coefficient characteristics.

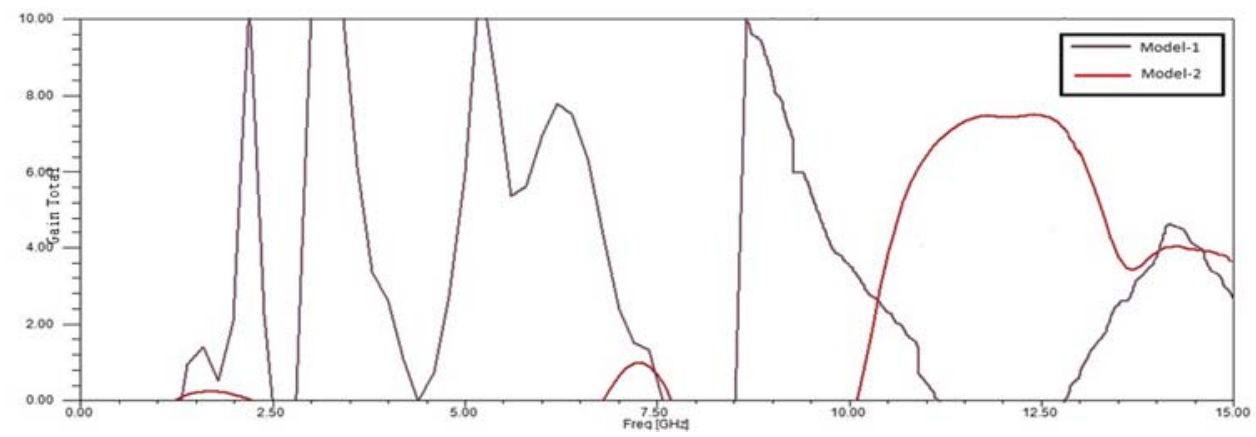

Figure 13. Gain Vs Frequency

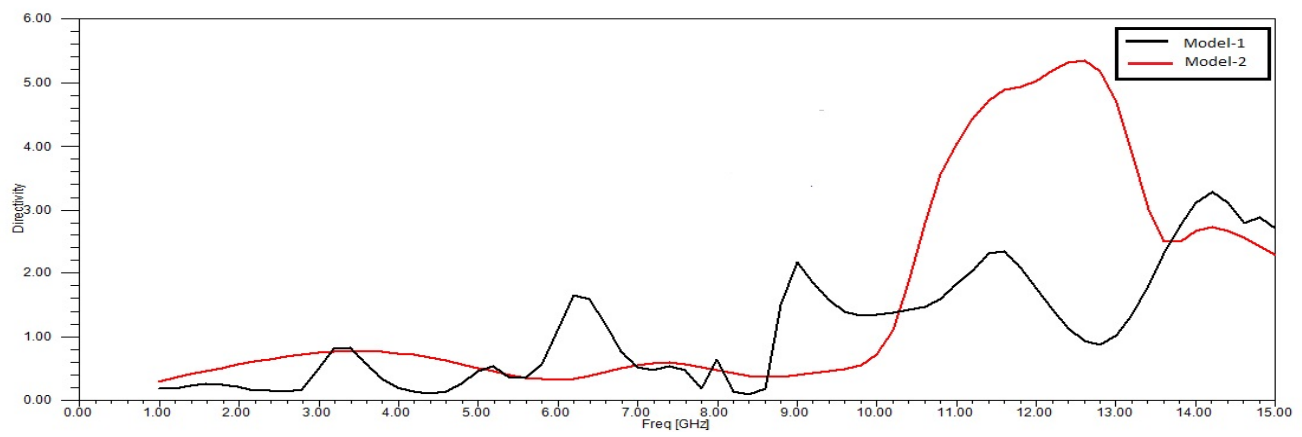

Figure 14. Directivity Vs Frequency

Figure 16 shows the parametric analysis with change in length of the feedline for antenna model2 by keeping width constant. Antenna is showing better reflection coefficient characteristics for length $\mathrm{L}=5 \mathrm{~mm}$. 


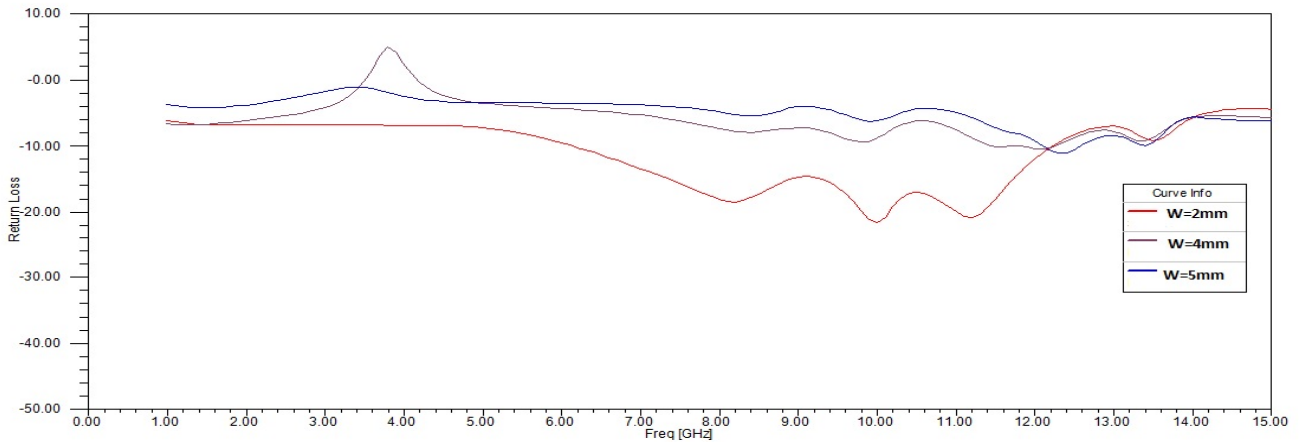

Figure 15. Parametric Analysis with change in feed line width 'W'

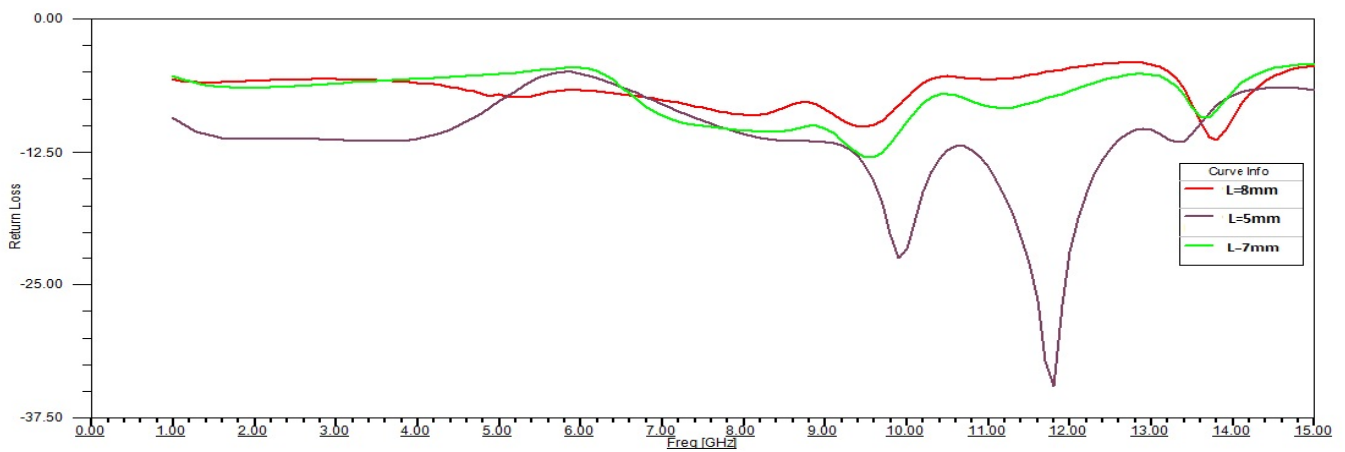

Figure 16. Parametric Analysis with change in feed line length ' $\mathrm{L}$ '

Figure 17 shows the fabricated antenna on FR4 substrate material. The top view and bottom view of the prototyped antenna can be observed with SMA connector. Figure 18 shows the measured reflection coefficient of the antenna on ZNB 20 vector network analyzer. The measured results are showing similar kind of results when compared the simulation results of HFSS.

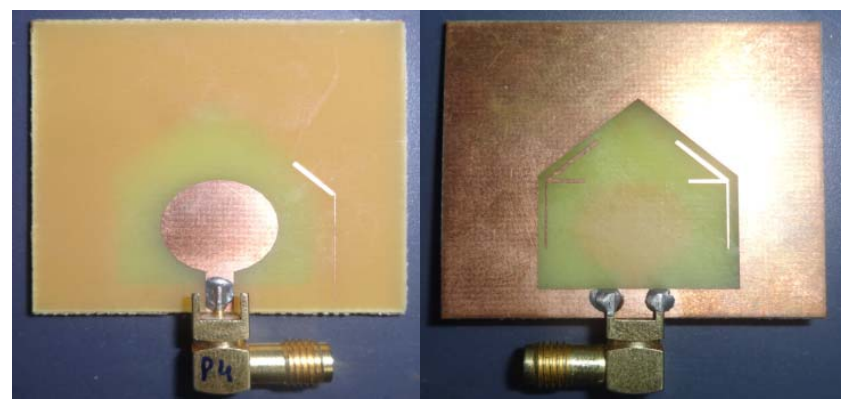

Figure 17. Fabricated Antenna Front view and Back view 


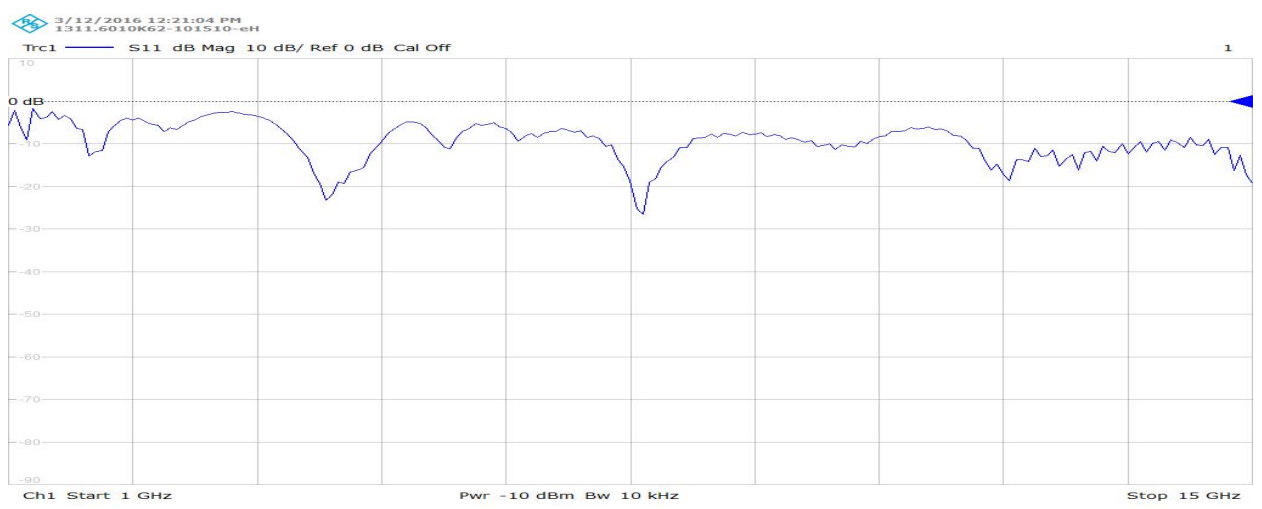

Figure 18. Measured Reflection Coefficient of the Antenna Model 2 on ZNB 20 VNA

\section{CONCLUSION}

Parasitic strip loaded notch band antennas are designed and analyzed in this work. Rectangular element based antenna is notching triple band and circular element based antenna is notching dual band in the desired ultra wideband range. Antennas are designed on FR4 substrate and simulation results are analyzed with HFSS tool. The prototyped antenna model of circular monopole with parasitic strip is providing excellent reflection coefficient and gain characteristics in the desired band. At notch bands antenna is showing degradation in the gain and poor radiation characteristics. The defected ground structure is providing additional resonant frequencies along with fundamental resonant frequency in the design. The proposed antenna measured results are in good agreement with the simulated results.

\section{ACKNOWLEDGEMENTS}

Authors like to express their gratitude towards the department of ECE and management of K L University for their support and encouragement during this work. Further we like to express our gratitude to DST through FIST grant SR/FST/ETI-316/2012.

\section{REFERENCES}

[1] N. Feiz, F. Mohajeri, A. Ghaznavi. Optimized Microstrip Antennas with Metamaterial Superstrates Using Particle Swarm Optimization,” Bulletin of Electrical Engineering and Informatics. 2013; 2(2): 123-131.

[2] B. T. P. Madhav, et al., "Liquid crystal polymer substrate based wideband tapered step antenna," Leonardo Electronic Journal of Practices and Technologies, ISSN 1583-1078, issue 26, pp. 103-114, 2015.

[3] B. T. P. Madhav, et al., "CPW Fed Antenna for Wideband Applications based on Tapered Step Ground and EBG Structure,” Indian Journal of Science and Technology, ISSN: 0974-6846, vol/issue: 8(9), pp. 119-127, 2015.

[4] C. Deng, et al., "CPW-fed planar printed monopole antenna with impedance bandwidth enhanced,” IEEE Antennas Wireless Propagation Letters, vol. 8, pp. 1394-1397, 2009.

[5] S. S. M. Reddy, et al., "Asymmetric Defected Ground Structured Monopole Antenna for Wideband Communication Systems," International Journal of Communications Antenna and Propagation, ISSN: 2039-5086, vol/issue: 5(5), pp. 256-262, 2015.

[6] B. T. P. Madhav, et al., "Analysis of Defected Ground Structure Notched Monopole Antenna," ARPN Journal of Engineering and Applied Sciences, ISSN 1819-6608, vol/issue: 10(2), pp. 747-752, 2015.

[7] B. T. P. Madhav, et al., "Novel Printed Monopole Trapezoidal Notch Antenna with S-Band Rejection," Journal of Theoretical and Applied Information Technology, ISSN: 1992-8645, vol/issue: 76(1), pp. 42-49, 2015.

[8] P. Lakshmikanth, et al., "Printed Log Periodic dipole antenna with Notched filter at $2.45 \mathrm{GHz}$ Frequency for wireless communication applications,” Journal of Engineering and Applied Sciences, ISSN: 1816-949X, vol/issue: 10(3), pp. 40-44, 2015. DOI: 10.3923/jeasci.2015.40.44.

[9] D. S. R. Kiran and B. T. P. Madhav, "Novel compact asymmetrical fractal aperture Notch band antenna," Leonardo Electronic Journal of Practices and Technologies, ISSN 1583-1078, vol/issue: 27(2), pp. 1-12, 2015.

[10] M. L. S. N. S. Lakshmi, et al., "Novel Sequential Rotated 2x2 Array Notched Circular Patch Antenna,” Journal of Engineering Science and Technology Review, ISSN: 1791-2377, vol/issue: 8(4), pp. 73-77, 2015.

[11] K. V. L. Bhavani, et al., "Multiband Slotted Aperture Antenna with Defected Ground Structure for C and X-Band Communication Applications,” Journal of Theoretical and Applied Information Technology, ISSN: 1992-8645, vol/issue: 82(3), pp. 454-461, 2015.

[12] D. S. Ramkiran, et al., "Compact Microstrip Band pass Filter with Defected Ground Structure,” Far East Journal of Electronics and Communications”, ISSN: 0973-7006, vol/issue: 15(1), pp. 75-84, 2015. 
[13] M. J. Almalkawi and V. K. Devabhaktuni, "Quad band-notched UWB antenna compatible with WiMAX/INSAT/lower-upper WLAN applications,” Electron. Lett., vol/issue: 47(19), pp. 1062-1063, 2011.

[14] M. Al-Husseini, et al., "A reconfigurable frequency-notched UWB antenna with split-ring resonators," in Proc. Asia-Pacific Microw. Conf., pp. 618-621, 2012.

[15] Y. Zhang, et al., "Planar ultra wideband antennas with multiple notched bands based on etched slots on the patch and/or split ring resonators on the feed line,” IEEE Trans. Antennas Propag., vol/issue: 56(9), pp. 3063-3068, 2008. 